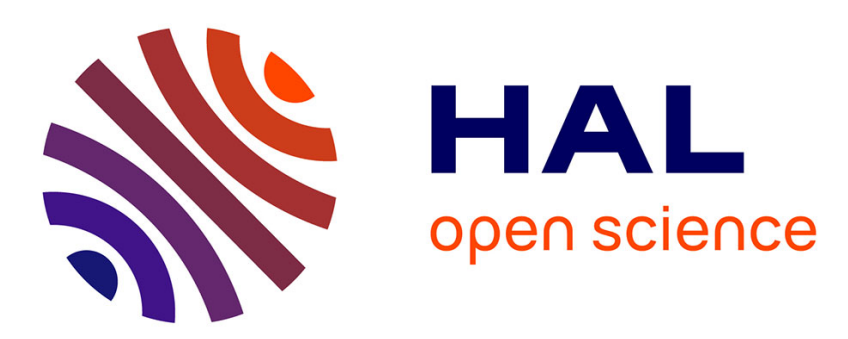

\title{
The origin of present-day Antarctic precipitation from surface snow deuterium excess data
}

\author{
P. Ciais, J. White, J. Jouzel, J. Petit
}

\section{To cite this version:}

P. Ciais, J. White, J. Jouzel, J. Petit. The origin of present-day Antarctic precipitation from surface snow deuterium excess data. Journal of Geophysical Research, 1995, 100 (D9), pp.18.917-18.927. 10.1029/95JD01169 . hal-02923793

\section{HAL Id: hal-02923793 \\ https://hal.science/hal-02923793}

Submitted on 4 Feb 2021

HAL is a multi-disciplinary open access archive for the deposit and dissemination of scientific research documents, whether they are published or not. The documents may come from teaching and research institutions in France or abroad, or from public or private research centers.
L'archive ouverte pluridisciplinaire $\mathbf{H A L}$, est destinée au dépôt et à la diffusion de documents scientifiques de niveau recherche, publiés ou non, émanant des établissements d'enseignement et de recherche français ou étrangers, des laboratoires publics ou privés. 


\title{
The origin of present-day Antarctic precipitation from surface snow deuterium excess data
}

\author{
P. Ciais, ${ }^{1,2}$ J. W. C. White, ${ }^{2}$ J. Jouzel, ${ }^{1,3}$ and J. R. Petit ${ }^{3}$
}

\begin{abstract}
The deuterium excess $(d)$ is defined as a linear combination of the $\mathrm{D} / \mathrm{H}$ and ${ }^{18} \mathrm{O} /{ }^{16} \mathrm{O}$ ratios in natural waters. We present an interpretation of deuterium excess data in surface Antarctic snow, using an isotopic model to derive information on the origin of present-day Antarctic precipitation. The data come from near the coast (D47, Adelie Land) and from inland (south pole, $1000 \mathrm{~km}$ from the sea). The one-dimensional isotopic model belongs to the Rayleigh family but fully accounts for mixed cloud processes between $0^{\circ} \mathrm{C}$ and $-30^{\circ} \mathrm{C}$. Modeling $d$ in polar snowfalls meets the problem of a large sensitivity to the saturation conditions prevailing at snow formation. Therefore we decided to tune the saturation in the model in order to yield realistic mean $d$ values, but we use the seasonal phase of $d$ versus $\delta$, which is less sensitive to the saturation conditions, as an independent validation of the model predictions. Both inland and near the coast, our model can simulate the observed phase between $d$ and $\delta$ in snow with moisture of subtropical origin $\left(40^{\circ}-20^{\circ} \mathrm{S}\right)$. Although we do not treat specifically storm precipitation near the coast, this study indicates that the observed phase between $d$ and $\delta$ brings up a new validation of isotopic models. It supports a distant vapor source for large-scale precipitation delivered to the Antarctic continent.
\end{abstract}

\section{Introduction}

Water isotopes deuterium and oxygen 18 have found applications in such diverse fields as cloud physics, climatology, hydrology, and paleoclimate studies. Usually, isotopic field measurements are combined with the modeling of isotopic fractionation occurring at various stages of the water cycle, and the interpretation takes advantage of the relationships that exist between isotopic distributions and various, generally climate-related, parameters. In polar snow isotope studies, increasing attention has been given to the deuterium excess $d$, first introduced by Dansgaard [1964], which is defined as the linear combination of $\delta \mathrm{D}$ and $\delta^{18} \mathrm{O}$ :

$$
d=\delta \mathrm{D}-8 \delta^{18} \mathrm{O}
$$

where the $\delta$ notation is used to express isotopic ratio $R$ relative to the SMOW standard as

$$
\delta=\frac{R-R_{\text {SMOW }}}{R_{\text {SMOW }}} \times 1000
$$

The factor of 8 has been chosen from the meteoric water line, which scales the $\delta \mathrm{D}$ versus $\delta^{18} \mathrm{O}$ distribution of global precipitation [Craig, 1961]. It is well known that in polar regions, both $\delta \mathrm{D}$ and $\delta^{18} \mathrm{O}$ are linear functions of the local temperature. Since definition (1) eliminates that first-order temperature dependence, $d$ is a proxy of climatic variables that are present,

\footnotetext{
${ }^{1}$ Laboratoire de Modélisation du Climat et de l'Environnement, Gif sur Yvette, France

${ }^{2}$ Stable Isotope Laboratory, Institute of Arctic and Alpine Research, University of Colorado, Boulder.

${ }^{3}$ Laboratoire de Glaciologie et de Géophysique de l'Environnement, St. Martin d'Hères, France.

Copyright 1995 by the American Geophysical Union.

Paper number 95JD01169.

0148-0227/95/95JD-01169\$05.00
}

but are otherwise masked, in the isotope-temperature relationship. In other words, $d$ can be regarded as a residual that relates to the (slight) differences between isotopes $\mathrm{D}$ and ${ }^{18} \mathrm{O}$. These differences come physically from a proportionally greater kinetic versus thermodynamic fractionation for molecule $\mathrm{H}_{2}{ }^{18} \mathrm{O}$ compared to molecule HDO.

Attempts to derive climatic information from the deuterium excess have related $d$ values on the ice sheet to sea surface temperature and sea surface humidity at the initial evaporation [Jouzel et al., 1982; Johnsen et al., 1989; Petit et al., 1991]. Such studies have shown that the saturation condition of the water vapor during snow formation plays a large role in the $d$ values predicted by isotopic models [Jouzel and Merlivat, 1984]. Unfortunately, very little is known about this latter variable, and this has put a limit on the ability to derive ocean source variables from the measurement of $d$ in snow. We address here the problem of deriving the origin of present-day Antarctic precipitation from the observed seasonality of $d$ versus $\delta \mathrm{D}$. We have selected two sites, $\mathrm{D} 47\left(154^{\circ} \mathrm{E}, 75^{\circ} \mathrm{S}\right.$, at $110 \mathrm{~km}$ from the sea), and South Pole station ( $1000 \mathrm{~km}$ from the sea) in order to examine the differences between coastal and inland regions.

The seasonality of isotope data in snow provides the annual mean values and the phase differences between $\delta$ and $d$. Since the annual mean $d$ is very sensitive to the saturation conditions, we have focused on the phase. The tool we used is a dynamically simple one-dimensional (1-D) isotopic model [Ciais and Jouzel, 1994], which treats processes occurring in idealized isolated air masses. This model is derived from the classic model of Jouzel and Merlivat [1984] and accounts realistically for the microphysical processes occurring in mixed clouds where the airborne condensed phase is composed of both ice crystals and liquid droplets. Conceptually, it has the advantage of using a continuous saturation curve for the air mass condensation history and hence of improving the modeling of $d$ in the temperature range $0^{\circ} \mathrm{C}$ to $-30^{\circ} \mathrm{C}$. Values of $\delta$ and $d$ predicted by this new model are nevertheless fairly close 
to those found by previous isotopic models, and they are in fair agreement with the observations [Ciais and Jouzel, 1994].

\section{Observations}

\subsection{Preserved Seasonal Variations of $D$ and ${ }^{18} O$ in Snow}

Few data sets resolve the seasonal cycle in Antarctica because of the low rate of accumulation. In the interior, seasonal variations in $\delta$ are not preserved in the firn owing to low accumulation. Near the coast, precipitation is 10 times larger than inland, and the $\delta$ of snow shows seasonal variations characterized by maximum $\delta$ in summer and minimum in winter. However, the roughness at the ice sheet surface and the scouring by wind probably yield irregularities in the snow stratigraphy that may erase, at least in part, the yearly isotopic signal [Pettre et al., 1986; Whillans, 1975]. Diffusion of isotopic water vapor in the firn pores smoothes high frequencies in the seasonal signal. In addition, diffusion acts as a low-pass filter and yields a smooth annual signal from isotopically distinct precipitation events [Whillans and Grootes, 1985]. In Greenland ice, when the $\delta$ wavelength is below $\approx 20 \mathrm{~cm}$ of ice, diffusion blurs the annual signal [Johnsen, 1977].

The data from South Pole $\left(9 \mathrm{~g} \mathrm{~cm}^{-2} \mathrm{yr}^{-1}\right)$ and D47 (26.7 $\mathrm{g}$ $\mathrm{cm}^{-2} \mathrm{yr}^{-1}$ ) should be blurred by diffusion, but they show wellpreserved seasonal oscillations, indicating that diffusion is inhibited either by low temperatures or by the presence of ice layers in the firn. Yet, because some isotopic years are likely missing in the records, we only examine the average $d-\delta$ phase over the total duration of our data. The same treatment is also applied to D47, where katabatic winds disturb the annual layering of snow [Parish and Wendler, 1991].

\subsection{Inland Data}

Two snow pits were sampled in situ during the 1977-1978 and 1983-1984 field seasons: the "1978 pit" and "1984 pit." The sampling increment being $2 \mathrm{~cm}$, one annual cycle represents 10 samples. The 2-m-long 1984 pit exhibits 9 annual cycles, and the 5-m-long 1978 pit has 20 annual cycles (data are plotted in Figures 1a and 1b). The experimental precision of our mass spectrometer is $0.5 \% 0$ in $\delta \mathrm{D}$ and $0.1 \% \circ$ in $\delta^{18} \mathrm{O}$, yielding an accuracy in the $d$ data of $1 \%$, roughly $20 \%$ of the annual amplitude. Both the 1978 and 1984 data show a large short-term variability, which we filtered out in the time domain using spline functions to cut out spikes lower than $1 \%$.

Aldaz and Deutch [1967] have shown that $\delta \mathrm{D}$ and $\delta^{18} \mathrm{O}$ at South Pole are a maximum in summer (December-January) and minimum in winter (March-November). However, the excess has a distinct phase, being in general highest during the fall and lowest during spring, and therefore lagging $\delta$ by 1 to 6 months. It is interesting to note that a similar lag of $d$ versus $\delta$ is also reported for central Greenland [Johnsen et al., 1989]. For further comparison with model runs which deal with an average year, we attempted to quantify the value of the $d-\delta$ phase by scaling the data in the range $[0,1]$ in both the time and $\delta$ directions to present them in an idealized average year (Figure 2). Figure 2 indicates an average lag of 5 months of $d$ with respect to $\delta$.

\subsection{Adelie Land Data}

The D47 site is on the Dumont-D'Urville-Dome C traverse, at $110 \mathrm{~km}$ from the sea (elevation, $1550 \mathrm{~m}$; mean temperature, $-25^{\circ} \mathrm{C}$ ). During the 1988-1989 summer, high resolution sam-
Deulerium

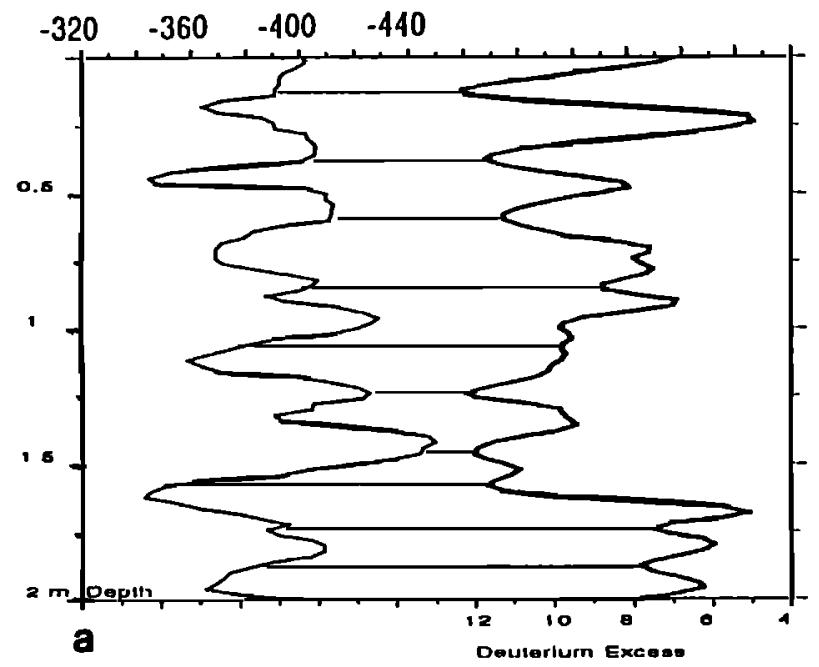

Figure 1. Plot of $\delta \mathrm{D}$ and excess as a function of depth in the (a) 1984 and (b) 1978 snow pits at South Pole and (c) the pit at site D47 (units are per mil versus SMOW). The short-term variability of the deuterium excess data is filtered out in the time domain using spline functions (see text).

pling of surface snow was made in a pit from 0 - to 10 -m depth with an increment of $3 \mathrm{~cm}$. Figure $1 \mathrm{c}$ shows $\delta \mathrm{D}$ and $d$ for the surface pit. The pit contains $24-26$ isotopic cycles, and despite possible reworking of snow by wind, we believe that the cycles' periodicity is 1 year because they yield an average accumulation rate of $21 \mathrm{~g} \mathrm{~cm}^{-2} \mathrm{yr}^{-1}$ comparable to the $\beta$ radioactivity value of $26.7 \mathrm{~g} \mathrm{~cm}^{-2} \mathrm{yr}^{-1}$ (M. Pourchet, unpublished data, 1990 ). Below $7 \mathrm{~m}$, annual variations in $\delta$ are dampened, possibly owing to diffusion in firn. A scaled plot of the average year for $\delta \mathrm{D}$ and $d$ is given in Figure 2. In contrast to South Pole data, $d$ and $\delta \mathrm{D}$ vary in phase throughout the year.

\section{Modeling Monthly $\delta$ and Excess}

We model monthly isotopic composition of the precipitation at D47 and South Pole, based on meteorological data for the vapor formation and the poleward advection of moist air. We account specifically for (1) evaporation at the ocean surface, (2) poleward transport, and (3) condensation-precipitation yielding snow formation in polar clouds. Points 1 and 2 are considerably simplified. Unlike GCM studies, we consider idealized air masses isolated from the outside air for both ocean evaporation and transport. We also simulate one single average monthly precipitation, neglecting the fact that $\delta$ in snow results from several distinct precipitation events, each having a different origin.

We want to make a preliminary study of the $d-\delta$ phase in Antarctica using a robust and inexpensive model to test several different sources of vapor. We used the 1-D model of Ciais and Jouzel [1994], where the amount of moisture in the cloud is controlled by a prescribed sequence of temperature and pressure. As the moist air "moves" poleward, it undergoes several condensation events and removals of the condensed phase by precipitation. 
Deulerium

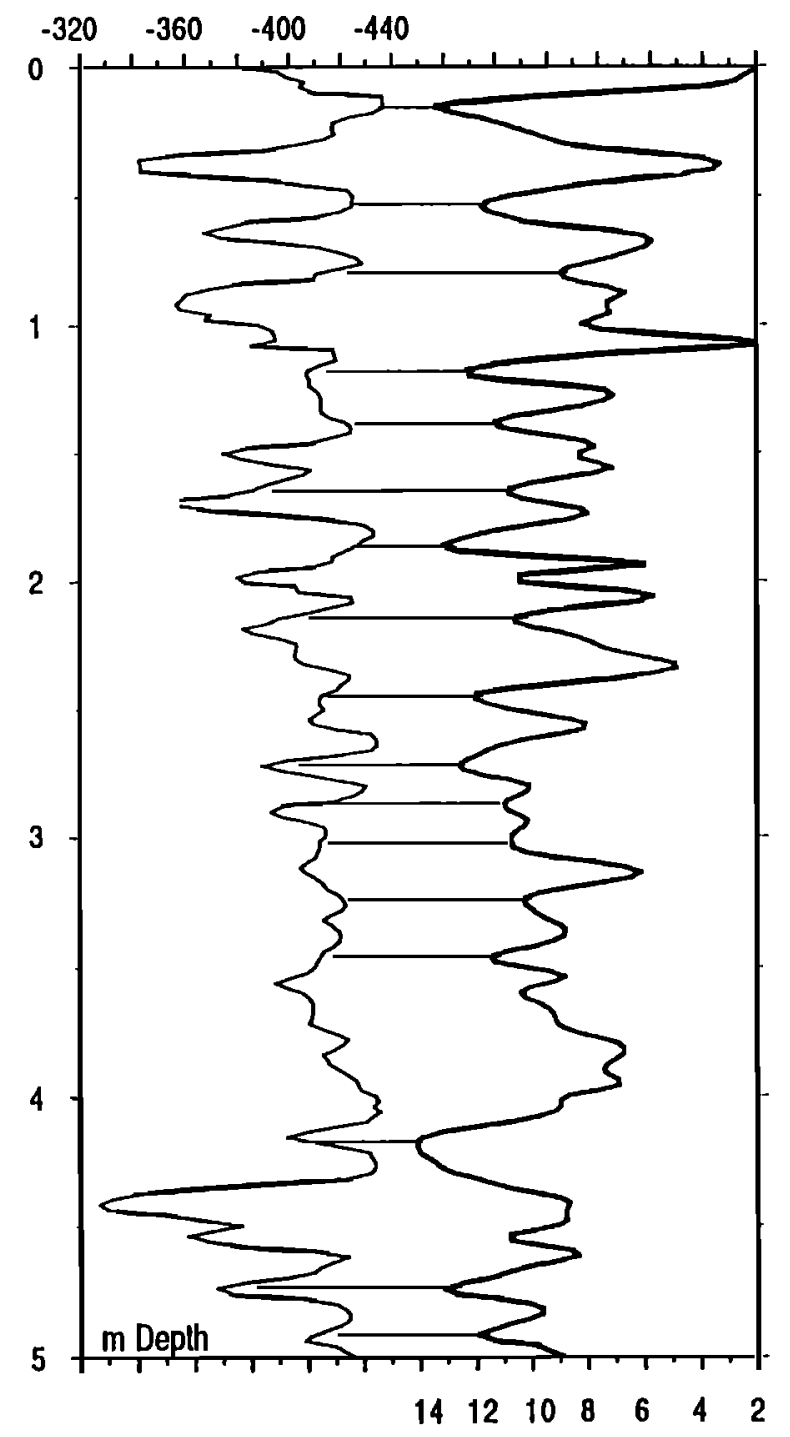

b
Deuterium Excess
Deulerium

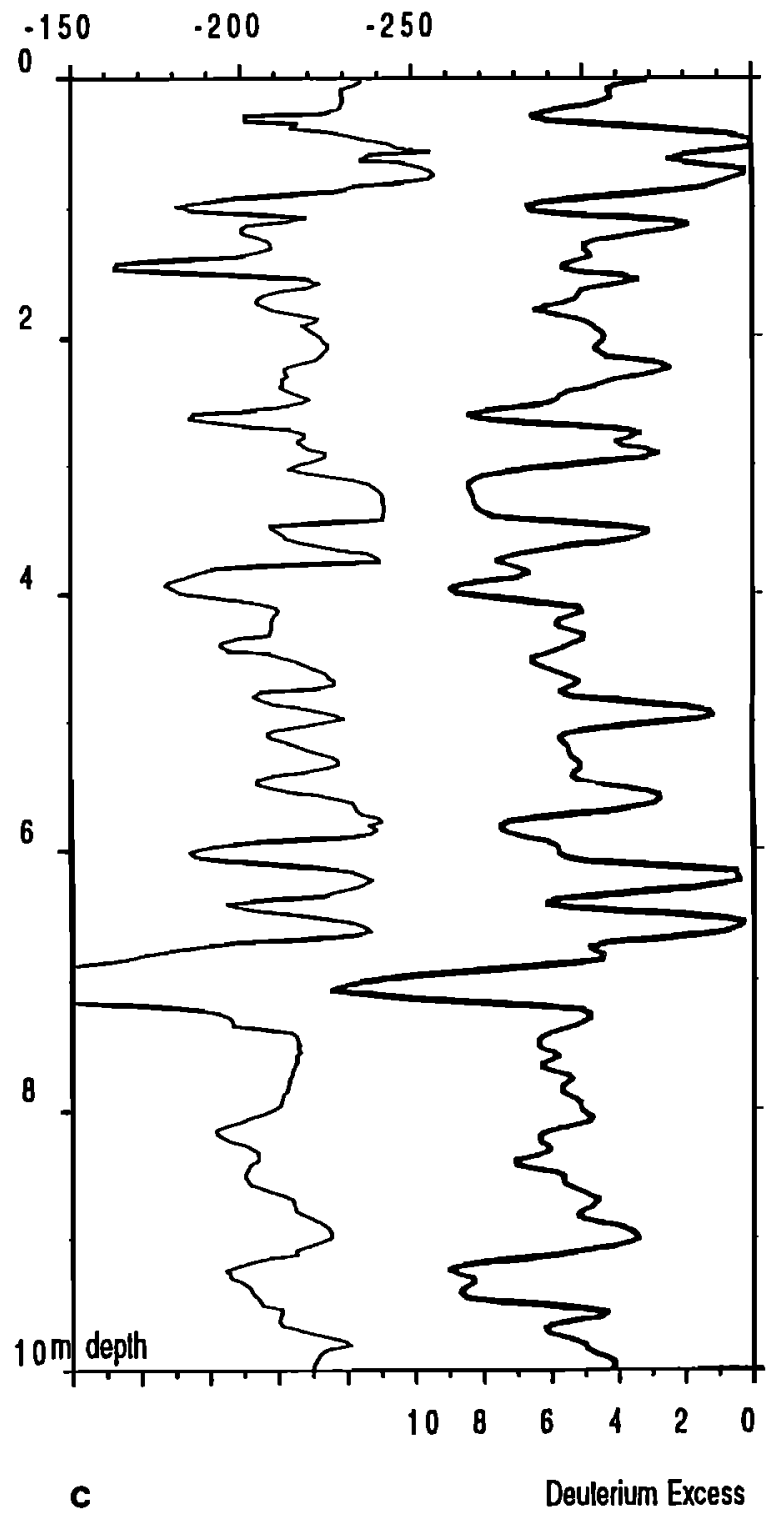

Figure 1. (continued)
We deal with the vapor-liquid equilibrium until the temperature is low enough to allow the formation of ice, typically $-5^{\circ} \mathrm{C}$. At this point we let ice crystals and water droplets coexist in the cloud down to $-30^{\circ} \mathrm{C}$. This coexistence occurs because the vapor is supersaturated versus cloud ice and undersaturated versus water [Mason, 1971]. Isotopically, we account for additional kinetic fractionation during the growth of ice crystals and the evaporation of liquid droplets [Jouzel and Merlivat, 1984; Fisher, 1991; Ciais and Jouzel, 1994]. The mixed cloud isotopic model (MCIM) has the advantage of suppressing the discontinuity in the supersaturation function when ice is formed, a necessary improvement for D47, although minor for South Pole.

\subsection{Vapor Formation}

Following Merlivat and Jouzel [1979], we calculate $\delta$ of the initial vapor $\left(\delta_{v_{0}}\right)$ at the ocean surface after Brutsaert [1975], the ocean composition $\delta_{\text {sea }}$ being inspired by Fisher [1992]:

$$
1+\delta_{v_{0}}=\frac{1}{\alpha_{e}} \frac{(1-k)}{(1-k h)}\left(1+\delta_{\mathrm{sea}}\right)
$$

Three variables related at the ocean surface determine $\delta_{\nu_{0}}$ : first, the sea surface temperature (SST $=T_{e}$ ) contained in the fractionation factor ( $\alpha_{e}$ from Majoube [1971]); second, the 10-m wind speed $w$ contained in the evaporation coefficient $k$; and third, the relative humidity above the ocean surface $(h)$. Note that when $h=1$, the initial $\delta_{v_{0}}$ and excess depend on $T_{e}$ only. We compiled monthly values of $\left(T_{e}, w, h\right)$ from available global data sets. Despite constant updating, the data coverage of the southern high latitudes is limited. For instance, there are no more than 1000 data in the Comprehensive OceanAtmosphere Data Set (COADS) between $50^{\circ} \mathrm{S}$ and $60^{\circ} \mathrm{S}$ over the past 30 years. We do not consider vapor formation in sea ice areas, although strong evaporation may occur from polynyas and contribute to precipitation near the coast [Barkov, 1985; Enomoto and Ohmura, 1992]. 


\section{D47 Pit}

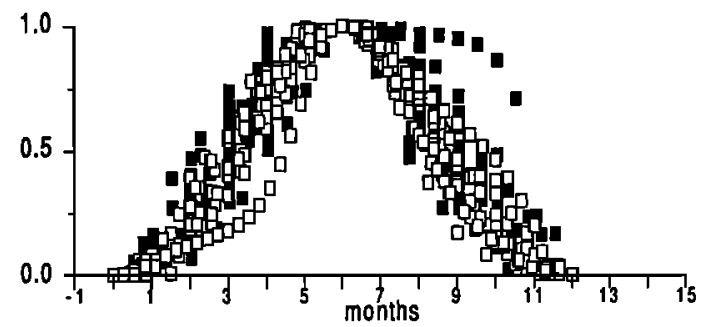

South Pole Pit 1978

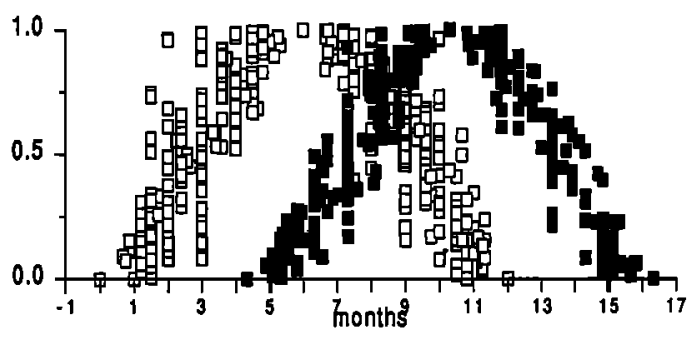

\section{South Pole Pit 1984}

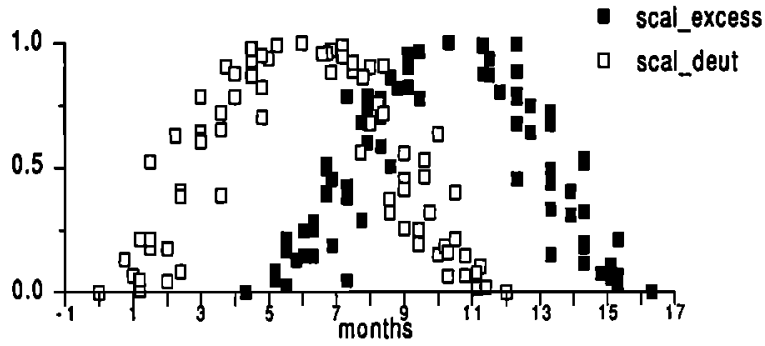

Figure 2. Average seasonality of $\delta \mathrm{D}$ and $d$ at South Pole and D47. The plot is constructed after the data shown in Figure 1. Both $\delta$ and excess are scaled in the range $[0,1]$ in the $\delta$ direction to present an idealized average year. The phase corresponds to the average phase difference observed between excess and $\delta$.

We use COADS climatology data for SST [Woodruff et al., 1987; Climate Research Program, 1985]. Commonly, SST decreases poleward with a steep gradient across the polar front. From the $2^{\circ} \times 2^{\circ}$ original data set, we made zonal averages every $10^{\circ}$ latitude between $20^{\circ} \mathrm{S}$ and $60^{\circ} \mathrm{S}$, plotted in Figure 3. The peak-to-peak amplitude of the zonally averaged SST is about $5^{\circ} \mathrm{C}$ north of $40^{\circ} \mathrm{S}$ but decreases to zero at high latitudes. Minimum SST occurs in August at $30^{\circ} \mathrm{S}$ and in October at $50^{\circ} \mathrm{S}$.

We use objectively analyzed wind data from the European Centre for Medium-Range Weather Forecasts (ECMWF) [Trenberth et al., 1989]. The zonally averaged wind increases poleward between $20^{\circ} \mathrm{S}$ and $40^{\circ} \mathrm{S}$, then decreases south of $60^{\circ} \mathrm{S}$. Figure 3 indicates maximum winds in winter. At around $50^{\circ} \mathrm{S}$, the data show biannual maxima, with two peaks in March and October [Trenberth, 1975]. This feature, first discovered by Van Loon [1967], is likely overestimated in the ECMWF data because of the scarcity of ship measurements in winter.

We use COADS relative humidity computed from dew point and air temperatures. Figure 3 plots the COADS data after objective analysis by Trenberth et al. [1989]. Low humidity characterizes the latitude $30^{\circ} \mathrm{S}$, corresponding to the subtropical high-pressure belt. Humidity increases poleward of $40^{\circ} \mathrm{S}$, and the air above polar waters is close to saturation.

\subsection{Poleward Transport}

After evaporation, the moist air is lifted under a constant vertical temperature gradient $\left(6.5^{\circ} \mathrm{C} \mathrm{km}^{-1}\right)$ until the dew point is reached, then transported poleward to the ice sheet. In the MCIM model, each "air mass" is taken to be isolated from the outside air. The "transport" is controlled by the air mass temperature $T$, pressure $P$, and precipitation function. The precipitation function is adjusted to reproduce the observed $d$ versus $\delta \mathrm{D}$ in Antarctica [Petit et al., 1991; Qin et al., 1994]. To match this condition, precipitation must remove at least $90 \%$ of the condensed phase formed in the cloud, a reasonable constraint in view of the low water contents effectively found in polar stratiform clouds [Mason, 1971]. Isotopically, the removal of most of the condensed phase formed in the cloud means that the system is close to a Rayleigh distillation.

We compiled monthly $T$ and $P$ from several data sets (Figure 4). First, between $20^{\circ} \mathrm{S}$ and $55^{\circ} \mathrm{S}$ we take COADS air temperature and sea level pressure. Second, from $60^{\circ} \mathrm{S}$ to $65^{\circ} \mathrm{S}$, we likewise use monthly ground level $T$ and $P$ at Antarctic coastal stations averaged over the last 30 years [Jones and Imbert, 1987]. We exclude sites of the Antarctic peninsula, which has a distinct regional climate [Schwerdtferger, 1984], as well as $P$ data from sites higher than $100 \mathrm{~m}$ above sea level. Third, for the South Pole runs only, we use $T$ and $P$ measured over the Ross Ice Shelf and West Antarctica by automatic weather stations [Sievers et al., 1986, 1987, 1988]. By forcing the model under zonal $T$ and $P$, we do not account realistically for longitudinal patterns; i.e., we treat air masses that combine the average characteristics of several possible tracks over the ice sheet. Indeed, we made tests to verify that the simulated $\delta$ at South Pole are not very sensitive to the specific track of the air over West Antarctica.

\subsection{Temperature Inversion and Height of Advection}

Over central Antarctica the cold dry surface air is often overlain by a warmer and moister layer. This phenomenon determines a positive upward temperature gradient, or temperature inversion [Dalrymple, 1966; Phillpot and Zillman, 1970]. The inversion is maximum in winter and almost disappears during the summer. In our model we assume that the air is advected preferentially in the inversion layer. We include the inversion based on vertical profiles obtained at South Pole and in West Antarctica [Schwerdtferger, 1970, 1984], assuming no inversion over sea ice (Figure 5). As the inversion temperature is determined by the energy budget of the inversion layer, where the radiative heat loss is compensated by vertical and horizontal motion, no additional radiative cooling of the air needs to be taken into account in our approach [Johnsen et al., $1989]$.

In the model, the moist air is advected poleward isobarically over the ocean, then according to a constant pressure difference with the ice sheet surface. We adopt for $\left(P_{\text {air mass }}-\right.$ $\left.P_{\text {surface }}\right)$ a value of 150 mbar, consistent with the hypothesis of air moving in the inversion layer. Although Petit et al. [1991] have demonstrated that a value of 50 mbar does not affect the modeled $d$ and $\delta$, we do not account for abrupt lifting of air parcels entering a cyclonic system or for local orographic lifting near the coast. 

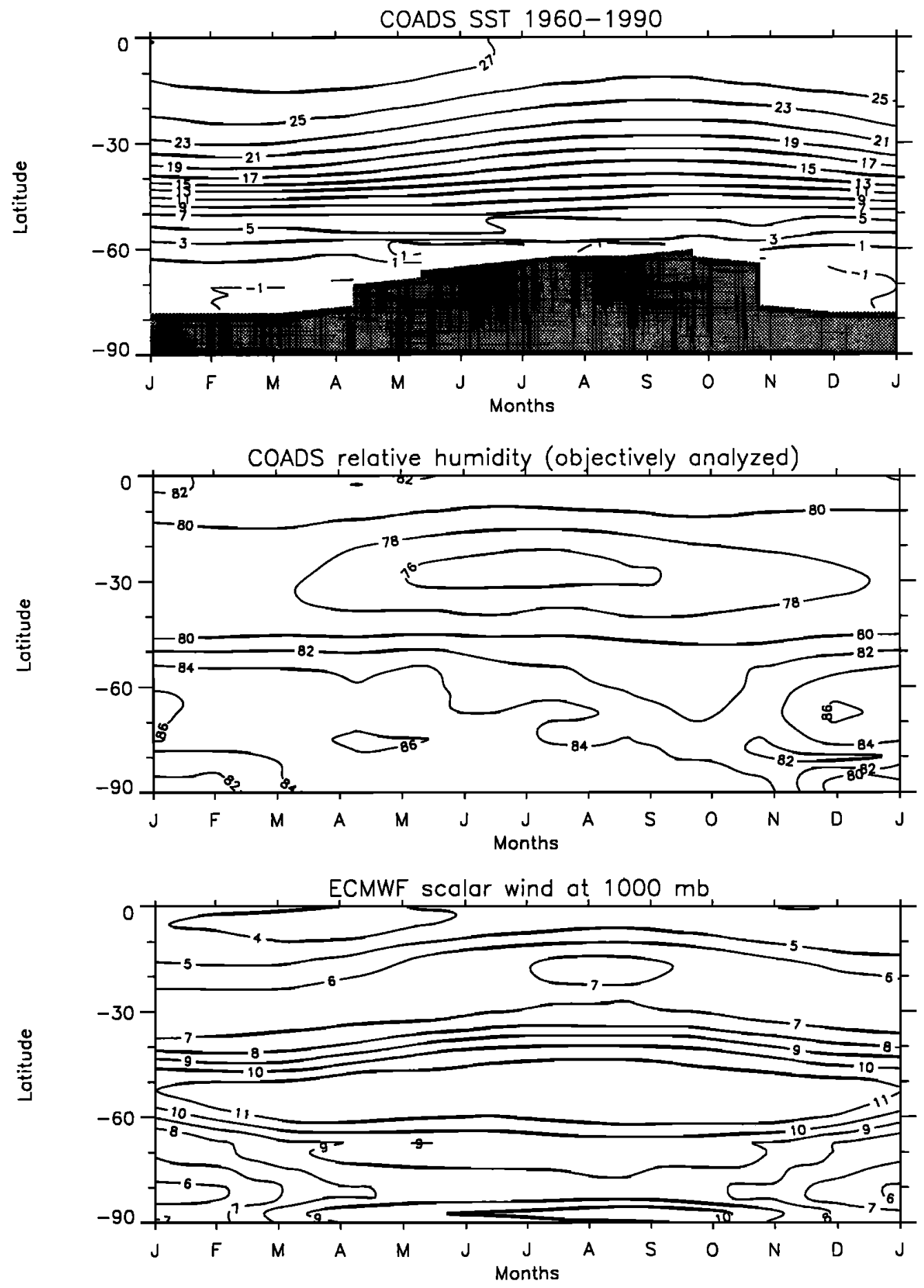

Figure 3. Latitude-time diagram of the parameters that control the formation of vapor and its isotopic composition. The sea surface temperature (SST), relative humidity, and wind speed data are monthly zonal averages over $10^{\circ}$ latitude bands (see text). Units are degrees Celsius for SST, percent for relative humidity, and meters per second for wind speed above sea level.

\section{Results and Discussion}

\subsection{Comparison of Model First-Stage Precipitation With Sub-Antarctic Data}

To evaluate the model predictions for early stages of condensation, we selected sites from the worldwide (IAEA) network: Pascua (Easter) Island $\left(27^{\circ} \mathrm{S}\right)$, Gough Island $\left(40^{\circ} \mathrm{S}\right)$, Falkland Islands (52 $\mathrm{S})$, and Argentine Island (64. $\mathrm{S})[L A E A$,
1981]. Figure 6 shows that except at Pascua, the excess varies in antiphase with $\delta$, as was noticed previously by Johnsen et al. [1989]. The data are compared with the model initial precipitation in Figure 6. The model successfully reproduces $d$ in antiphase with $\delta$, despite its simplified evaporation. On the other hand, the model overestimates $\delta$, possibly because the real world precipitation is not of strictly local origin as we assume in the model. Rather, it is probably formed from vapor 

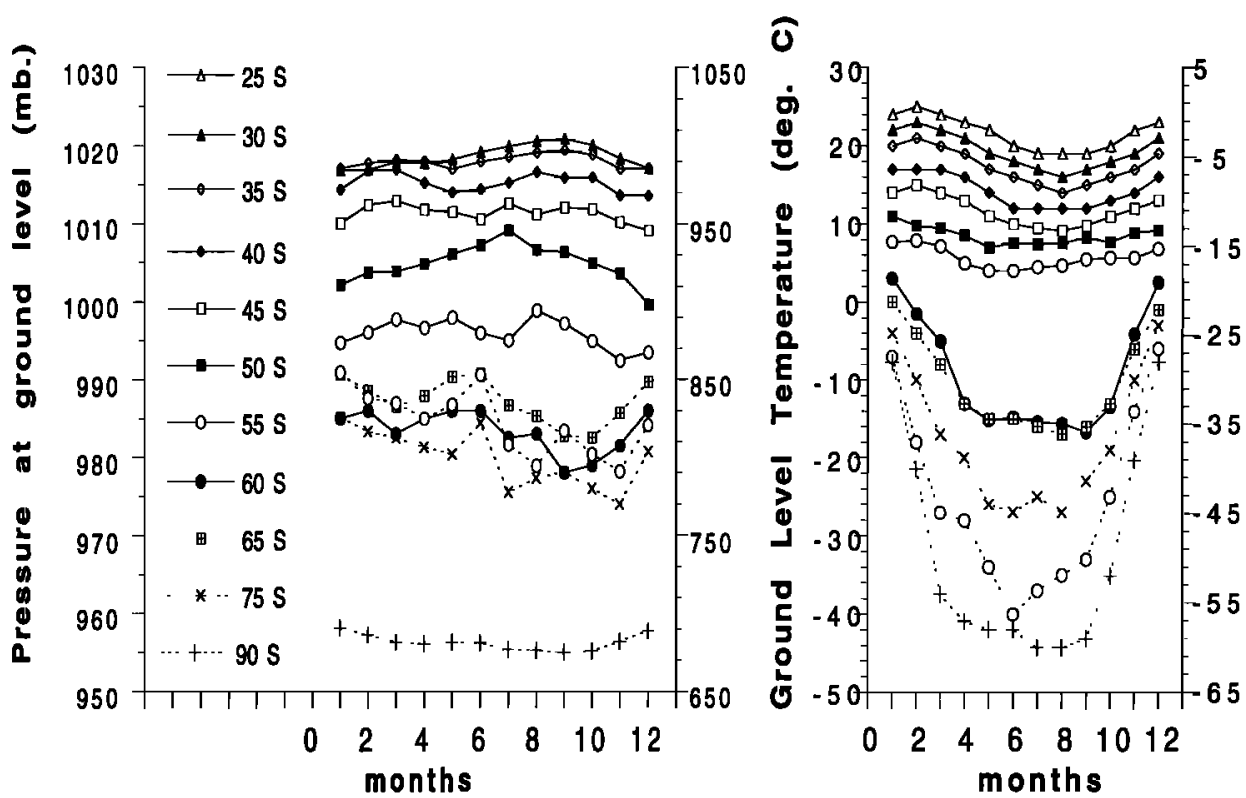

Figure 4. Monthly temperature and pressure used to calculate $\delta \mathrm{D}$ and $d$ in precipitation at South Pole and at D47. The model follows each monthly sequence of prescribed pressure and temperature. The data are a compilation of different meteorological data sets (see text). The temperature and pressure at South Pole station are on the right axis.

that has already undergone several condensations and hence is more depleted in heavy isotopes.

We run the model successively with different moisture sources, between $20^{\circ} \mathrm{S}$ and $60^{\circ} \mathrm{S}$. The air advected poleward is condensed according to $T$ and $P$ compiled in section 3.2 until the target site is reached. Monthly values of $\delta \mathrm{D}, \delta^{18} \mathrm{O}$, and $d$ have been calculated in that manner separately at South Pole and D47.

\subsection{Model Results at South Pole}

The model curves of $\delta \mathrm{D}$ at South Pole are plotted in Figure 7. The simulated $\delta \mathrm{D}$ compare reasonably well with the observations, except when the moisture comes from polar waters $\left(50^{\circ}-60^{\circ} \mathrm{S}\right)$. The model curves of $\delta \mathrm{D}$ present a broad minimum

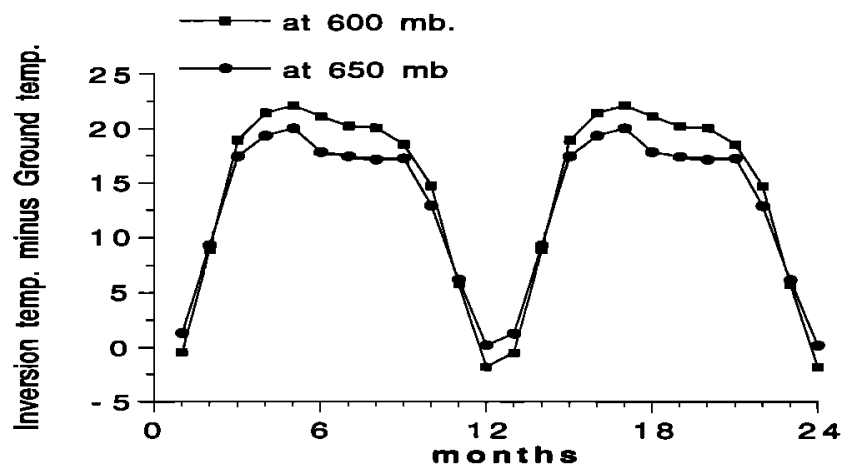

Figure 5. Inversion of temperature at South Pole, based on several years of in situ radiosounding measurements (repeated identically over 2 years for clarity). The curves plot the difference between temperature at a given height minus the value at ground level, which is roughly at 680 mbar. The average between 650 mbar and 600 mbar corresponds to the inversion height prescribed in the model. Note a strong inversion in winter, which almost cancels out in summer. associated with the "coreless" polar winter, roughly between April and October [Van Loon, 1967]. The maximum in $\delta \mathrm{D}$ corresponds to the summer period, December to January, consistently with in situ measurements of $\delta \mathrm{D}$ in snowfall at South Pole [Aldaz and Deutch, 1967; Jouzel et al., 1983]. It is clear that $\delta \mathrm{D}$ mimics the in situ temperature course, with a short summer peak coming out of an eight-month-long winter. Our seasonal simulations thus support the idea that $\delta \mathrm{D}$ at South Pole is controlled primarily by local temperature, rather than by the air mass history or by the precipitation mechanism. The latitude of the moisture source influences the model mean $\delta \mathrm{D}$ values by up to a few tenths of a permil, polar sources yielding to overestimate $\delta \mathrm{D}$. The most realistic minimum and maximum $\delta \mathrm{D}$ in the model correspond to sources between $20^{\circ}$ and $40^{\circ} \mathrm{S}$. On the other hand, the phase of $\delta \mathrm{D}$ is practically independent of the source of vapor.

The model curves of excess in Figure 7 indicate that $d$ is sensitive to the source. Moisture originating from higher latitudes with identical conditions in supersaturation yields lower annual mean excess (the model would even produce negative $d$ when moisture comes from polar waters). We force the annual mean excess to match the observations by tuning the supersaturation function $S_{i}$, within the physical limits of saturation with respect to ice and saturation with respect to liquid water [Petit et al., 1991]. The values used for $S_{i}$ are given in Figure 7. We nevertheless verify that the phase between $d$ and $\delta$ is not sensitive to the supersaturation function we use, which makes the phase an independent criterion in selecting realistic moisture sources from the model curves in Figure 7. The phase difference between $d$ and $\delta \mathrm{D}$ is linked to the moisture source. A source at $30^{\circ} \mathrm{S}$ yields the best agreement with the data, with a 3-month lag of $d$ versus $\delta \mathrm{D}$ ( $d$ is maximum in fall and minimum in summer). A source located in polar areas, south of $40^{\circ} \mathrm{S}$, yields a 6-month lag of $d$ versus $\delta \mathrm{D}$ ( $d$ is maximum in winter and minimum in summer). A source near the coast $\left(60^{\circ} \mathrm{S}\right)$ overestimates the minimum in $d$ produced by the model. 

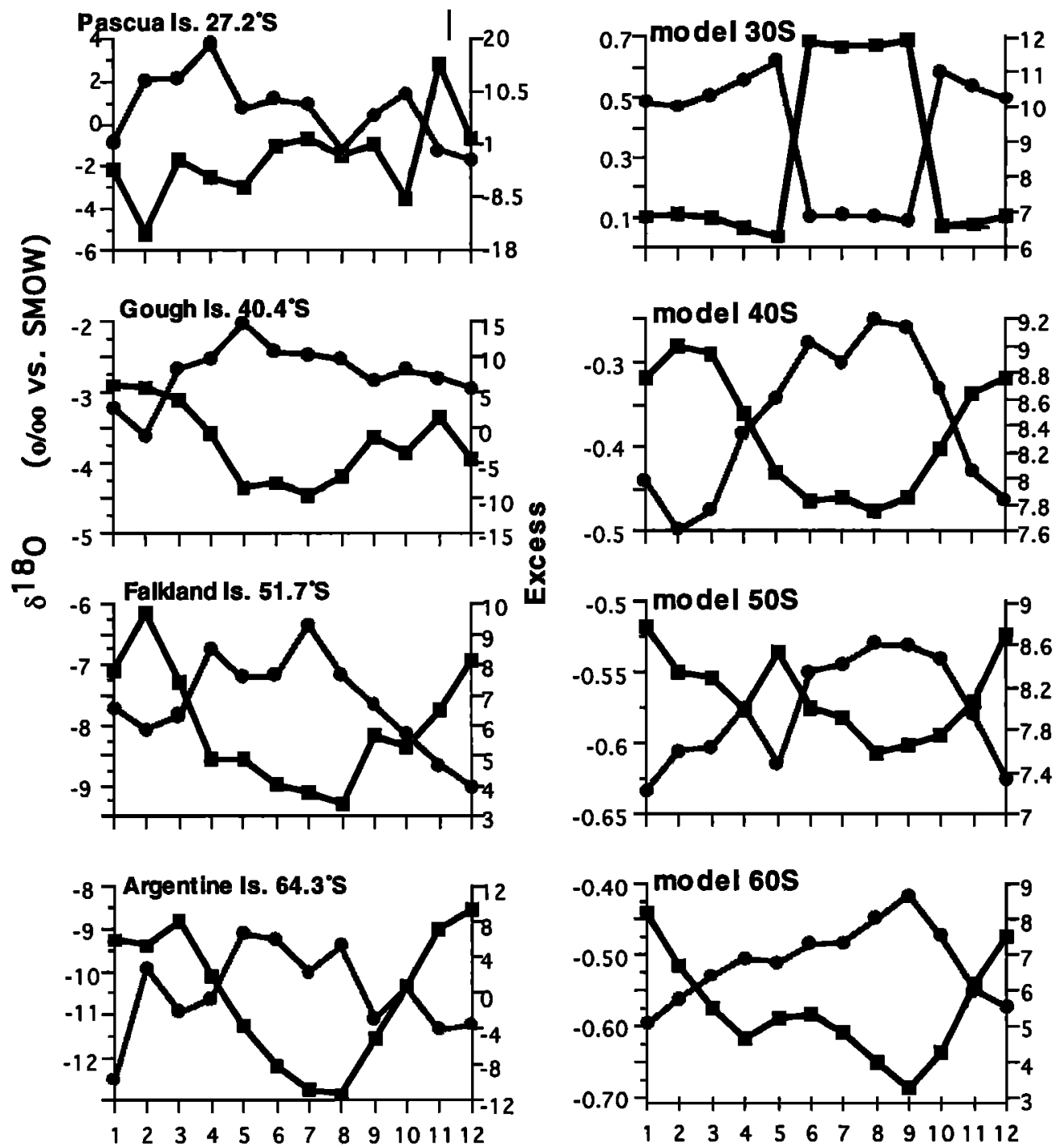

months

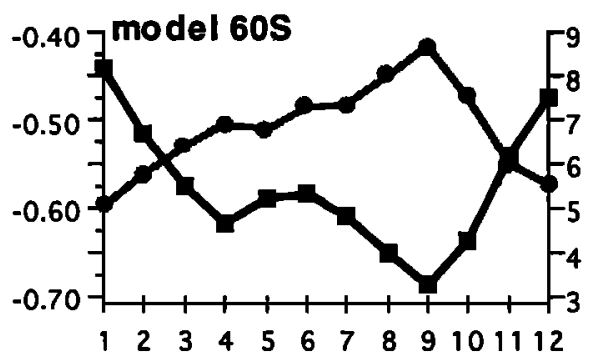

Figure 6. Model curves showing the $\delta^{18} \mathrm{O}$ (squares) and deuterium excess (circles) of the first-stage precipitation in the model, compared with observations at maritime sites at corresponding latitudes of the International Atomic Energy Agency network. The 6-month phase difference of $d$ versus $\delta$ is reproduced correctly by the model, but $\delta^{18} \mathrm{O}$ in the first-stage precipitation is overestimated by the model (see text for discussion).

\subsection{Model Results at $D 47$}

The model curves of $\delta \mathrm{D}$ at D47 are shown in Figure 8. They show some similarities with the model results at South Pole, including maximum $\delta \mathrm{D}$ in summer and minimum values in winter. However, the summer peak in $\delta \mathrm{D}$ is larger for $\mathrm{D} 47$ than for South Pole because the summer is longer on the coast. When the source of moisture is set in subtropical waters $\left(20^{\circ}-\right.$ $40^{\circ} \mathrm{S}$ ), the mean $\delta \mathrm{D}$ is $50 \%$ more negative than the data. The discrepancy is smaller if moisture comes from polar waters $\left(50^{\circ}-60^{\circ} \mathrm{S}\right)$. Isotopically, the underestimation of $\delta \mathrm{D}$ starting with a warm source may reflect an "overdistillation" of the air in the model, because air masses are considered as isolated systems from the evaporation to the polar precipitation.

Monthly excess simulated by the model at D47 is plotted in Figure 8. We tune the supersaturation function in the model to obtain realistic annual mean values of the excess. In contrast to South Pole, the tuning of the supersaturation at D47 has an effect on the $d-\delta$ phase: we observed that changing $S_{\imath}$ can shift $d$ by up to 3 months with respect to $\delta$. This means that the phase of $d$ versus $\delta$ also depends on the supersaturation function near the coast. No fit of the supersaturation to the annual mean value of $d$ at D47 was possible if the source is in polar waters at $50^{\circ}-60^{\circ} \mathrm{S}$. In this latter case, the annual mean $d$ is negative, whereas the observations indicate low but positive excess values. Considering the phase, if the moisture source is taken north of $40^{\circ} \mathrm{S}$, the predicted excess tends to be in phase with $\delta \mathrm{D}$, hence producing a rather good agreement with the phase of the data. On the other hand, if the moisture derives from polar waters $\left(50^{\circ}-60^{\circ} \mathrm{S}\right)$, the predicted excess is out of phase with $\delta \mathrm{D}$ by up to 6 months. 

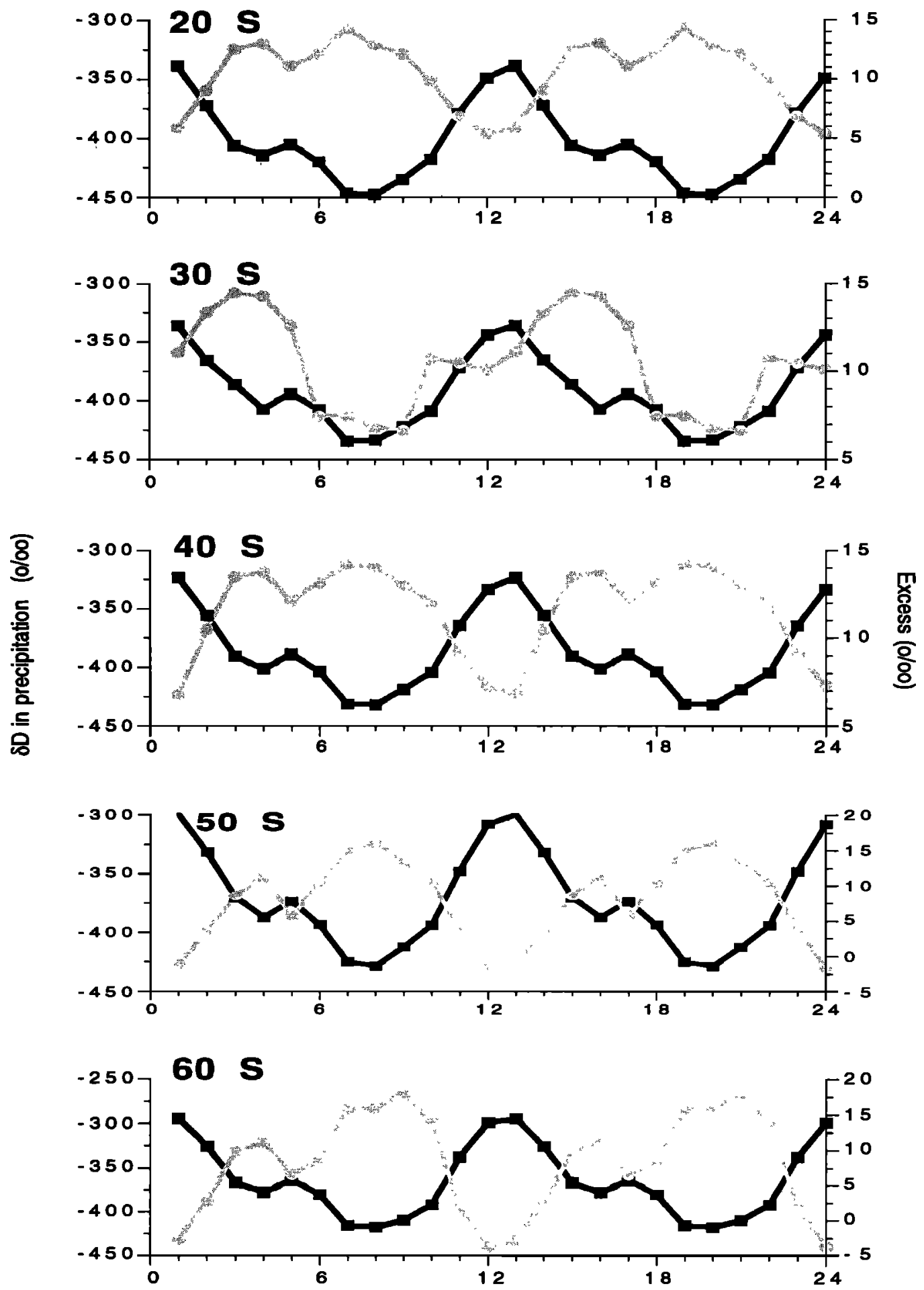

Figure 7. Model curves showing monthly $\delta \mathrm{D}$ and excess in snowfall at South Pole. The black curve is $\delta \mathrm{D}$, and the gray curve is excess $\left(\delta^{18} \mathrm{O}\right.$ has exactly the same phase as $\left.\delta \mathrm{D}\right)$. Each plot corresponds to a run with a different moisture source latitude between $20^{\circ} \mathrm{S}$ and $60^{\circ} \mathrm{S}$. The average model curve is repeated identically over 2 years for clarity. In each plot, the supersaturation of vapor with respect to ice $\left(S_{i}\right)$ is a linear function of the temperature at ground level $\left(T_{g}\right)$. These functions are determined to yield the best possible fit to the annual mean excess data. The functions used are as follows: $20^{\circ} \mathrm{S}, S_{i}=1.05-0.0041 T_{g} ; 30^{\circ} \mathrm{S}, S_{t}=1.04-$ $0.0040 T_{g} ; 40^{\circ} \mathrm{S}, S_{i}=1.02-0.0038 T_{g} ; 50^{\circ} \mathrm{S}, S_{i}=1.02-0.0020 T_{g}$; and $60^{\circ} \mathrm{S}, S_{i}=1.00-0.0015 T_{g}$.

\subsection{Discussion}

A simple 1-D isotopic model is capable of reproducing the seasonality of $\delta \mathrm{D}$ and excess both inland and near the coast. Such a fair behavior of the model may be a consequence of a relatively simple moisture transport from the southern ocean to Antarctica in the real world. Although $\delta \mathrm{D}$ and $\delta^{18} \mathrm{O}$ are sensitive primarily to the temperature of precipitation, the second-order parameter $d$ depends strongly on the source of moisture. As has been shown by previous modeling works, the annual mean value of $d$ can always be adjusted to the obser- 

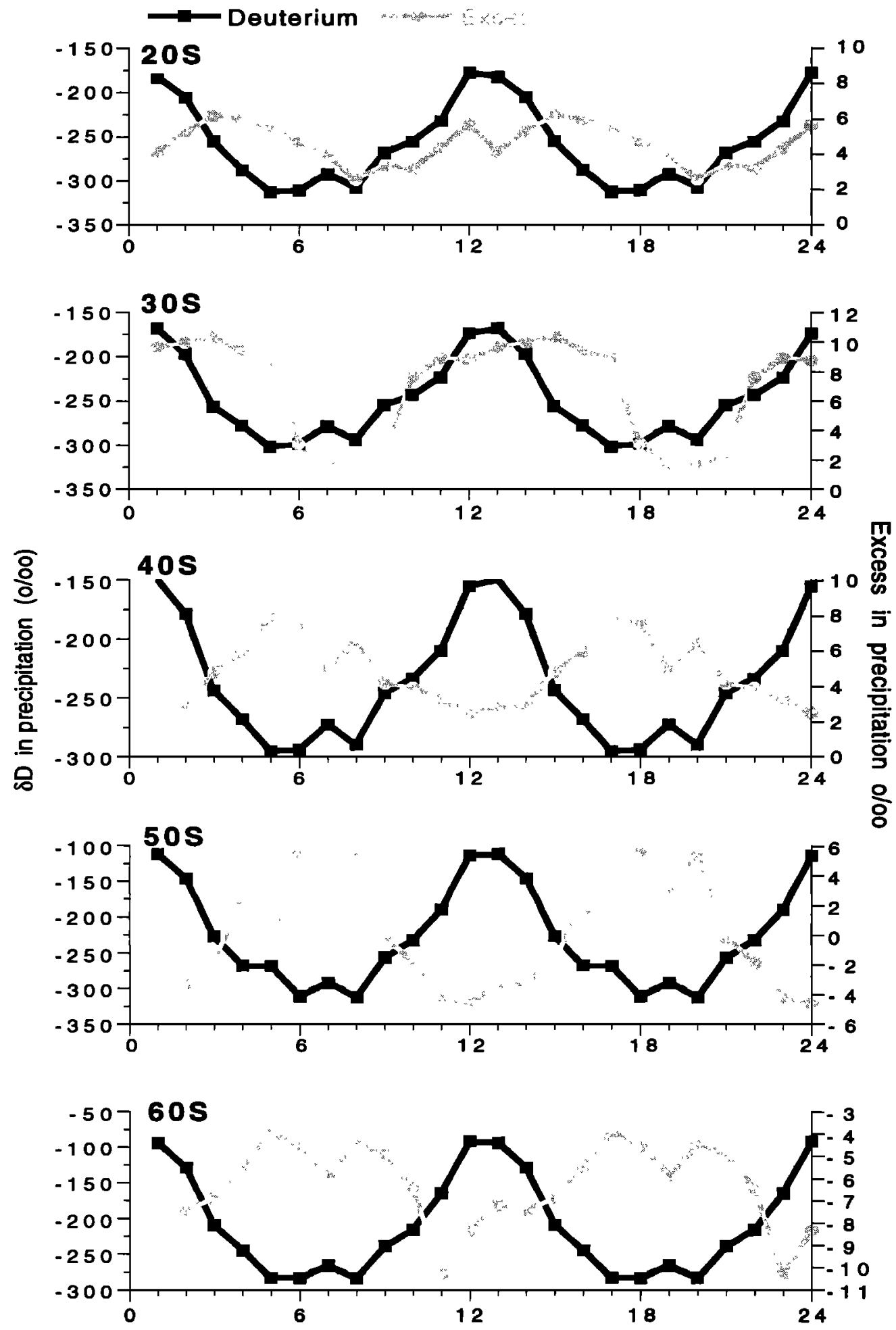

Figure 8. Same as Figure 7 for D47. No fit of the supersaturation function to the annual mean excess data was possible starting with moisture formed in polar water $\left(50^{\circ}-60^{\circ} \mathrm{S}\right)$. In that case, we adopted the closest fit to the data. The functions used are as follows: $20^{\circ} \mathrm{S}, S_{t}=1.05-0.0041 T_{g} ; 30^{\circ} \mathrm{S}, S_{t}=1.03-0.0020 T_{g}$; $40^{\circ} \mathrm{S}, S_{\imath}=1.02-0.0020 T_{g} ; 50^{\circ} \mathrm{S}, S_{i}=1.01-0.0010 T_{g} ;$ and $60^{\circ} \mathrm{S}, S_{i}=1.00-0.0010 T_{g}$.

vations by playing on the supersaturation function. In contrast, the $d-\delta$ phase relationship is less sensitive to the supersaturation function than is the annual $d$ value. Therefore we believe that the phase is an independent constraint to infer the information on the vapor source contained in the excess.

In the case of South Pole, we find that the data are compat- ible with a subtropical moisture source, located between $20^{\circ} \mathrm{S}$ and $40^{\circ} S$ (Table 1). The phase between $d$ and $\delta \mathrm{D}$ does not makes it possible to separate clearly one particular latitude, but the best agreement between model and data corresponds to a source at $30^{\circ} \mathrm{S}$ ( $d$ lagging $\delta$ by 3 months). In summer a source in polar waters yields unrealistic low values of excess at South 
Table 1. Comparison of Observed and Modeled Deuterium D and Deuterium Excess $d$ in Inland and Coastal Antarctic Precipitation

\begin{tabular}{|c|c|c|c|c|c|c|c|}
\hline & \multicolumn{3}{|c|}{ Deuterium, \%o versus SMOW } & \multicolumn{3}{|c|}{ Excess, \%o versus SMOW } & \multirow{2}{*}{$\begin{array}{c}\text { Lag of } d \\
\text { versus D } \\
\text { months }\end{array}$} \\
\hline & Mean & Minimum & Maximum & Mean & Minimum & Maximum & \\
\hline \multicolumn{8}{|c|}{ Inland (South Pole) } \\
\hline \multicolumn{8}{|l|}{ Data } \\
\hline 1978 pit & -400 & -450 & -330 & 5 & 2 & 14 & $3-5$ \\
\hline 1984 pit & -390 & -450 & -340 & 9 & 5 & 12 & $2-3$ \\
\hline \multicolumn{8}{|l|}{ Model } \\
\hline $20^{\circ} \mathrm{S}$ & -402 & -447 & -338 & 10 & 5 & 14 & $4-6$ \\
\hline $30^{\circ} \mathrm{S}$ & -393 & -435 & -336 & 10 & 7 & 14 & $2-3$ \\
\hline $40^{\circ} \mathrm{S}$ & -387 & -431 & -323 & 11 & 7 & 14 & $4-7$ \\
\hline $50^{\circ} \mathrm{S}$ & -373 & -429 & -300 & 8 & -2 & 16 & $5-7$ \\
\hline $60^{\circ} \mathrm{S}$ & -365 & -418 & -294 & 8 & -4 & 18 & $5-6$ \\
\hline \multicolumn{8}{|c|}{ Coast (D47) } \\
\hline Data & -210 & -250 & -150 & 5 & 0 & 9 & 0 \\
\hline \multicolumn{8}{|l|}{ Model } \\
\hline $20^{\circ} \mathrm{S}$ & -257 & -313 & -178 & 5 & 3 & 6 & $2-3$ \\
\hline $30^{\circ} \mathrm{S}$ & -247 & -300 & -168 & 7 & 2 & 10 & $1-2$ \\
\hline $40^{\circ} \mathrm{S}$ & -235 & -295 & -150 & 5 & 3 & 8 & $4-5$ \\
\hline $50^{\circ} \mathrm{S}$ & -227 & -312 & -113 & 0 & -5 & 6 & $4-5$ \\
\hline $60^{\circ} \mathrm{S}$ & -209 & -280 & -92 & -6 & -10 & -4 & $4-5$ \\
\hline
\end{tabular}

Pole. Yet it would be possible to match the South Pole data by setting moisture to originate from anywhere between $60^{\circ} \mathrm{S}$ and $30^{\circ} \mathrm{S}$ in winter but only from the sub-tropical oceans in summer.

The case of D47 is more complicated. The model $\delta \mathrm{D}$ would favor a source in polar waters, which is excluded by the modeled excess. The pit isotope measurements could be matched by the model run with a subtropical vapor source (no phase lag of $d$ versus $\delta$ ), but only if additional moisture of local polar waters is added to the system. Nevertheless, the model curves for D47 must be taken cautiously because our model does not include the complex mechanism of precipitation near the coast due to strong orographic lifting of clouds. Cyclones formed at low latitudes and heading for Antarctica deliver significant amount of precipitation under storm events [Bromwich, 1988]. These storms, frequently breaking the winter inversion, are characterized by large supersaturations, which have the potential to influence the value of the excess in snow [Fisher, 1991]. At face value, we believe from the present model curves that subtropical vapor must be a nonnegligible source of Antarctic precipitation near the coast.

A physical justification for the differences in $d-\delta$ phase between inland and coastal zones involves the number of condensations having occurred in the air parcel since its evaporation. The kinetic fractionation for oxygen 18 being larger than for deuterium, after numerous condensations, the moist air is relatively more depleted in ${ }^{18} \mathrm{O}$ than it is in $\mathrm{D}$. Therefore conceptually, more condensations produce higher $d$ values. This is already verified in the spatial distribution of excess (overall increase toward inland Antarctica), but we think that it also applies to the seasonality. In winter a larger temperature gradient prevails between ocean and inland Antarctica, which determines higher excess than during the summer. When numerous condensations are involved, this effect puts $d$ in antiphase with $\delta$, as it is the case in the real world at South Pole. Superimpased on this effect is the fact that $d$ is teleconnected to the vapor source. Simple models indicate that the source temperature controls $d$ at inland sites, whereas the source relative humidity dominates near the coast. Indeed we find that second-order changes in the phase lag of $d$ versus $\delta$ at South
Pole ( 3 months with a source at $30^{\circ} \mathrm{S}$ versus 6 months with a source at $60^{\circ} \mathrm{S}$ ) reflects the observed patterns of SST in the southern ocean. For D47, the lack of monthly relative humidity data at sub-Antarctic latitudes prevents us from concluding that $d$ is similarly controlled by the seasonal phase of the relative humidity.

\section{Conclusions}

We have examined the seasonality of deuterium, oxygen 18 , and deuterium excess in Antarctic snow, using data from two snow pits at D47 (near the coast) and South Pole (inland). Near the coast the excess varies in phase with $\delta$, but inland, $d$ lags $\delta$ by approximately 6 months. To gain understanding of this behavior, we have modeled the monthly isotopic composition of snow in a 1-D model parameterized by the temperature and pressure history of moist air from the vapor source to the ice sheet. The model also includes monthly modifications in the evaporative source, which further influence $d$ in Antarctic snow. We have made several test cases where the precipitation is derived from a single evaporative source located between $20^{\circ} \mathrm{S}$ to $60^{\circ} \mathrm{S}$. The contribution of each latitude is examined separately, as no mixing is allowed.

The model simulations are compared with the data, both for the annual mean values of $\delta$ and excess and for the $d-\delta$ phase. In the interior of Antarctica we obtain a reasonable fit with the observations with a source between $20^{\circ} \mathrm{S}$ and $40^{\circ} \mathrm{S}$, which suggests that polar waters may be a poor contributor to the moisture supply of the interior. Near the coast, we also infer a dominant moisture source in subtropical ocean gyres, but the model may not treat correctly local contributions to storm precipitation. Our results support the study of Koster et al. [1992] who find in the Goddard Institute for Space Studies GCM that interior regions of Antarctica have a warm moisture source. Using a more sophisticated model, we also confirm a similar conclusion of Petit et al. [1991] of the spatial distribution of the mean excess in polar snow.

Generally, a better understanding of the present-day excess is necessary to use long time series in ice cores as a proxy of 
changing vapor source in the past. In this work we have shown that in addition to the annual mean excess, the $d-\delta$ phase contains important information that can also help to validate further GCM simulations of the global HDO and $\mathrm{H}_{2}{ }^{18} \mathrm{O} \mathrm{cy}-$ cles. An appropriate mean of gaining further insights on the deuterium excess in polar regions would require to examine the $d-\delta$ phasing as well as the annual mean excess in a transect of snow pits going from the coast to the interior. Such a project can be addressed in the framework of planned glaciological traverses in Antarctica.

\section{References}

Aldaz, L., and S. Deutch, On a relationship between air temperature and oxygen isotope ratio of snow and firn in the south pole region, Earth Planet. Sci. Lett., 3, 267-274, 1967.

Barkov, N., Coastal climate of the Antarctic continent, in Ice Shelves of Antarctica, edited by E. S. Korotkevitch, Gidrometeorolorogia, St. Petersburg, Russia, 1985.

Bromwich, D. H., Snowfall in high southern latitudes, Rev. Geophys., 26, 149-168, 1988.

Brutsaert, W. A., Theory for local evaporation (or heat transfer) from rough and smooth surfaces at ground level, Water Resour. Res., 11, $543-550,1975$.

Ciais, P., and J. Jouzel, Deuterium and oxygen 18 in precipitation: An isotopic model including mixed cloud processes, J. Geophys. Res., 99 , 16,793-16,803, 1994.

Climate Research Program, Comprehensive Ocean-Atmosphere Data Set, release 1, Environ. Res. Lab., Boulder, Colo., 1985.

Craig, H., Isotopic variations in meteoric waters, Science, 133, 1702$1703,1961$.

Dalrymple, P. C., A physical climatology of the Antarctic plateau, in Studies in Antarctic Meteorology, Antarc. Res. Ser., vol. 9, edited by M. J. Rubin, pp. 195-231, AGU, Washington, D. C., 1966.

Dansgaard, W., Stable isotopes in precipitation, Tellus, 16, 436-468, 1964.

Enomoto, H., and A. Ohmura, Open water and the circumpolar trough in the Antarctic, Proc. NIPR Symp. Polar. Meteorol. Glaciol., 5, 104$112,1992$.

Fisher, D. A., Remarks on the deuterium excess in precipitation in cold regions, Tellus, Ser. B, 43, 401-407, 1991.

Fisher, D. A., Stable isotope simulations using a regional stable isotope model coupled to a zonally averaged global model, Cold Reg. Sci. Technol., 21, 61-77. 1992.

International Atomic Energy Agency (IAEA), Statistical Treatment of Environmental Isotope Data in Precipitation, Tech. Rep. Ser. LAEA, 206, 1-256, 1981.

Johnsen, S. J., Stable isotope homogeneisation of polar snow and ice, Isotopes and impurities in snow and ice, $L A H S$ Publ., 118, 210-218, 1977.

Johnsen, S. J., W. Dansgaard, and J. W. White, The origin of Arctic precipitation under present and glacial conditions, Tellus, 41, 452469, 1989.

Jones, P. D., and D. W. S. Imbert, A data bank of Antarctic surface temperature and pressure data, Rep. DOE/ER/60397-H2 TR038, Off. of Energy Res., Carbon Dioxide Res. Div., U.S. Dep. of Energy, Washington, D. C., 1987.

Jouzel, J., and L. Merlivat, Deuterium and oxygen 18 in precipitation: Modeling of the isotopic effects during snow formation, $J$. Geophys. Res., 89, 11,749-11,757, 1984.

Jouzel, J., L. Merlivat, and C. Lorius, Deuterium excess in an East Antarctic ice core suggests higher relative humidity at the oceanic surface during the last glacial maximum, Nature, 299, 688-691, 1982.

Jouzel, J., L. Merlivat, J. R. Petit, and C. Lorius, Climatic information over the last century deduced from a detailed isotopic record in the South Pole snow, J. Geophys. Res., 88, 2693-2703, 1983.

Jouzel, J., G. L. Russell, R. J. Suozzo, R. D. Koster, J. W. C. White, and W. S. Broecker, Simulations of the HDO and $\mathrm{H}_{2}{ }^{18} \mathrm{O}$ atmospheric cycles using the NASA/GISS general circulation model: The seasonal cycle for present-day conditions, J. Geophys. Res., 92, $14,739-14,760,1987$.

Koster, R. D., J. Jouzel, R. J. Suozzo, and G. L. Russel, Origin of July Antarctic precipitation and its influence on deuterium content: A GCM analysis, Clim. Dyn., 7, 195-203, 1992.

Majoube, M., Fractionnement en Oxygène 18 et en deutérium entre l'eau et sa vapeur, J. Chim. Phys. 10, 1473, 1971.

Mason, B. J., The Physics of Clouds, Oxford Univ. Press, New York, 1971 .

Merlivat, L., and J. Jouzel, Global climatic interpretation of the deuterium-oxygen 18 relationship for precipitation, J. Geophys. Res., 84, 5029-5033, 1979.

Parish, T., and G. Wendler, The katabatic wind regime at Adélie Land, Antarctica, Int. J. Climatol., 11, 91-107, 1991.

Petit, J. R., J. W. White, N. W. Young, J. Jouzel, and Y. S. Korotkevitch, Deuterium excess in recent Antarctic snow, J. Geophys. Res., 96, 5113-5123, 1991

Pettre, P., J. F. Pinglot, M. Pourchet, and L. Reynaud, Accumulation distribution in Terre Adélie, Antarctica: Effect of meteorological parameters, J. Glaciol., 32, 486-500, 1986.

Phillpot, H. R., and J. W. Zillman, The surface temperature inversion over the Antarctic continent, J. Geophys. Res., 75, 4161-4169, 1970.

Qin, D., J. R. Petit, J. Jouzel, and M. Stievenard, Distribution of stable isotopes in surface snow along the route of the 1990 international Trans-Antarctica expedition, J. Glaciol., 134, 107-118, 1994.

Schwerdtferger, W., The climate of the Antarctic, in Climate of the Polar Regions, World Surv. of Climatol., vol. 14, edited by S. Orvig, Elsevier, New York, 1970.

Schwerdtferger, W., Weather and Climate of the Antarctic, Dev. Atmos. Sci., vol. 15, Elsevier, New York, 1984.

Sievers, M. F., G. A. Weidner, and C. R. Stearns, Automatic Weather Station Data for the Calendar Year 1985, Univ. of Wis., Madison, 1986.

Sievers, M. F., G. A. Weidner, and C. R. Stearns, Automatic Weather Station Data for the Calendar Year 1986, Univ. of Wis., Madison, 1987.

Sievers, M. F., G. A. Weidner, and C. R. Stearns, Automatic Weather Station Data for the Calendar Year 1987, Univ. of Wis., Madison, 1988.

Trenberth, K. E., A quasi-biennial standing wave in the southern hemisphere and interrelations with sea surface temperature, $Q . J . R$. Meteorol. Soc., 101, 55-74, 1975.

Trenberth, K., J. Olson, and W. G. Large, A global ocean wind stress climatology based on ECMWF analyses, NCAR Tech. Note 338, Natl. Cent. for Atmos. Res., Boulder, Colo., 1989.

Van Loon, $\mathbf{H}$., The half-yearly oscillations in middle and high southern latitudes and the coreless winter, J. Atmos. Sci., 24, 472-486, 1967.

Whillans, I. M., Effect of inversion winds on topographic details and mass-balance on inland ice sheets, J. Glaciol., 14, 85-90, 1975.

Whillans, I. M., and P. M. Grootes, isotopic diffusion in cold snow and firn, J. Geophys. Res., 90, 3910-3918, 1985.

Woodruff, S. D., R. J. Slutz, R. L. Jenne, and P. M. Steurer, A Comprehensive Ocean-Atmosphere Data Set, Bull. Am. Meteorol. Soc., $68,1239-1249,1987$.

P. Ciais and J. Jouzel, Laboratoire de Modélisation du Climat et de l'Environnement, Bâtiment 709, L'Orme des Meurisiers, Centre Saclay, 91191 Gif sur Yvette, France. (e-mail: ciais@bofix.saclay.cea.fr.)

J. R. Petit, Laboratoire de Glaciologie et de Géophysique de l'Environnement, B.P. 76, 38600 St. Martin d'Hères, France.

J. W. C. White, Stable Isotope Laboratory, Institute of Arctic and Alpine Research, Campus Box 450, University of Colorado, Boulder, CO 80309.

(Received February 3, 1994; revised January 19, 1995; accepted February 21, 1995.) 